\title{
A fatal Clostridium perfringens infection with hemolysis after chemotherapy in an adolescent
}

\author{
Musa G. Kukul, M.D. ${ }^{a}$, Kısmet Ciki, M.D. ${ }^{a}$, Eda Karadag-Oncel, M.D. ${ }^{b}$, Ali B. Cengiz, M.D. ${ }^{b}$, \\ Baris Kuskonmaz, M.D. ${ }^{c}$, Betul Tavil, M.D. ${ }^{c}$ and Selman Kesici, M.D. ${ }^{d}$
}

\begin{abstract}
Gas gangrene, clostridial myonecrosis, is one of the most serious infectious diseases, characterized by rapidly progressive destruction of deep soft tissues and production of gas within the tissues. We presented a case of fatal spontaneous gas gangrene due to Clostridium perfringens in a patient with acute lymphoblastic leukemia during remission induction chemotherapy phase.

Key words: gas gangrene, child, hemolysis.
\end{abstract}

http:/ /dx.doi.org/10.5546/aap.2017.eng.e92

To cite: Kukul MG, Ciki K, Karadag-Oncel E, et al. A fatal Clostridium perfringens infection with hemolysis after chemotherapy in an adolescent. Arch Argent Pediatr 2017;115(2):e92-e95.

\section{INTRODUCTION}

Clostridia species are gram-positive sporeforming bacilli that give rise to $10 \%$ of anaerobic infections with a wide range of clinical sites. Several species have been described ( $C$. perfringens, C. novyi, C. septicum, C. bifermentans, C. sordellii, etc.), among which C. perfringens has been reported to be the most frequent cause of gas gangrene. ${ }^{1,2}$

a. Department of Pediatrics, Faculty of Medicine, Hacettepe University.

b. Department of Pediatrics, Division of Pediatric Infectious Diseases, Faculty of Medicine, Hacettepe University.

c. Department of Pediatrics, Pediatric Hematology, Faculty of Medicine, Hacettepe University.

d. Department of Pediatrics, Pediatric Intensive Care Unit, Faculty of Medicine, Hacettepe University.

E-mail address:

Eda Karadag-Oncel, M.D.: dredakaradag@gmail.com

Funding: None.

Conflict of interest: None.

Received: 6-28-2016

Accepted: 10-20-2016
Clostridia species are members of normal intestinal and vaginal flora, and are ubiquitous in soil. The vast majority of clostridial infections are of endogenous origin. Even those secondary to trauma and contamination of a wound with foreign bodies usually involve $C$. perfringens or other clostridia from the endogenous flora, mainly the intestinal tract. ${ }^{1,3}$

The spectrum of $C$. perfringens infection includes cellulitis, necrotizing fasciitis, and severe myonecrosis (gas gangrene). Clostridial myonecrosis may occur in the absence of a traumatic wound, so-called spontaneous myonecrosis, and is caused by bacteremic seeding of muscle with either $C$. perfringens or $C$. septicum. In spontaneous myonecrosis, the source of the bacteria typically is the intestines, and the common predisposing factors are mucosal damages of the intestines or ulcerations produced by cytotoxic chemotherapy. ${ }^{1-3}$

Clostridium myonecrosis is uncommon and mortality rate is up to $90 \%$ with early and aggressive treatment, especially in patients with an underlying malignancy, immunosuppression, and neutropenia. ${ }^{1,4}$ The prognosis for survival bound up with the disease severity and immediate therapeutic approach. Death is inevitable if surgical treatment is delayed. ${ }^{1,2}$ We present a fatal case of clostridial myonecrosis with hemolysis secondary to $C$. perfringens in an adolescent with acute lymphoblastic leukemia (ALL).

\section{CASE REPORT}

A 17-year-old boy admitted with complaints of fatigue and spontaneous epistaxis. Physical examination revealed hepatosplenomegaly and his laboratory results demonstrated moderate anemia, hyper leukocytosis and thrombocytopenia (hemoglobin $10.6 \mathrm{~g} / \mathrm{dl}$, WBC $404900 / \mathrm{mm}^{3}$ and platelets $52000 / \mathrm{mm}^{3}$ ). A bone marrow biopsy revealed ALL; leukapheresis was required two times, and chemotherapy was started.

On day 11 of chemotherapy, he began to suffer from severe abdominal pain, shortly after he complained of leg pain in the dorsal thigh. His abdomen was tender on examination 
and lower extremities were edematous and exquisitely tender; however, his pulses were palpable; crepitus, discoloration or erythema were not present. Laboratory examinations showed pancytopenia, with normal blood chemistry. There were neither infection signs, including fever, nor increased C-reactive protein. Abdominal ultrasonography was normal, with no specific finding suggesting neutropenic enterocolitis or any other abdominal pathology.

The pain persisted 6 hours and then the patient exhibited altered mental status and became progressively unresponsive. Physical examination was consistent with shock, with cold and pale extremities and filiform pulses. After blood cultures were obtained, empirical therapy with meropenem and vancomycin was started. He was intubated, intravenous fluid and positive inotropic medication were started immediately and transferred to the intensive care unit. Crepitation was noted in its right leg in the dorsolateral part of the thigh. Considering the possibility of necrotizing fasciitis and gas gangrene, clindamycin was added. Laboratory examination revealed pancytopenia and progression of anemia suggesting a massive hemolysis (hemoglobin $2.8 \mathrm{~g} / \mathrm{dl}$, white blood cell count $600 / \mathrm{mm}^{3}$ and platelet count $16000 /$ $\mathrm{mm}^{3}$ ) and blood product transfusions were made.

FIGURE 1 . Thigh radiograph of a child with gas gangrene and large amounts of subcutaneous and intramuscular gas are noted and showed with arrows

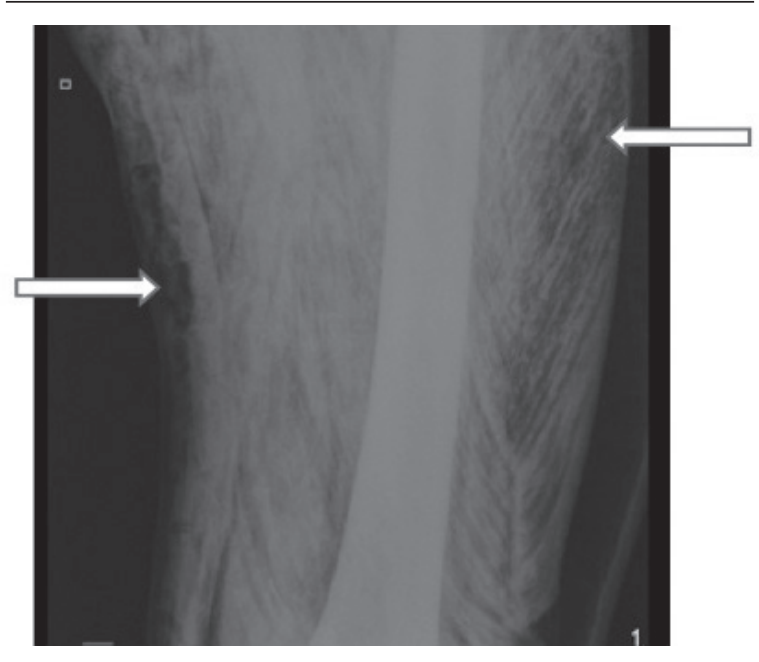

Radiological findings showed large amounts of subcutaneous and intramuscular gas (Figure 1) while orthopedic surgeon was consulted.

Cardiac arrest occurred within minutes. Cardiopulmonary resuscitation was unsuccessful and the patient died. After his death, the results of cultures came out. Escherichia coli was isolated at aerobic blood culture while culture obtained in an anaerobic manner by fluid aspiration from the quadratus muscle demonstrated C. perfringens.

\section{DISCUSSION}

Clostridium perfringens is an anaerobic gram positive bacillus found in soil and in the normal flora of skin and intestines. Clostridium perfringens is an unusual cause of bacteremia and sepsis. Clostridial spores mainly acquired via trauma or surgical wounds. C. perfringens is the major cause when gas gangrene occurs after trauma. ${ }^{2} \mathrm{C}$. septicum is the typical cause of spontaneous gas gangrene, which occurs in immunocompromised hosts, especially in patients receiving chemotherapy. Besides acquired neutropenia, cyclic and congenital neutropenia patients are also at risk, especially due to abdominal focus with increased risk if mucosal barrier is impaired. ${ }^{2}$

The likely source of $C$. perfringens infection in our case is the gastrointestinal tract, possible mucosal leakage at intestines, leading rapid spread to the blood stream. To date, several cases have addressed the gastrointestinal system as source of infection. In many reports, immunodeficiency secondary to aggressive chemotherapy appears to be most remarkable. Cytotoxic effects of chemotherapeutic agents on the gastrointestinal system cause a portal of entry into the blood stream. A relevant number of bloodstream infections are originated from bacterial penetration of the impaired mucosal barrier during neutropenia.

C. perfringens infections have a wide range of diseases, from self-limited gastroenteritis to a life-threatening gas gangrene. Clostridial myonecrosis, also known as gas gangrene, is a rare and devastating illness. Antibiotic therapy and surgical debridement should be immediately performed. Early surgical debridement is of critical value as concentrations of antibiotics do not reach optimal values within necrotic tissue. Penicillin and clindamycin are the standard therapies. ${ }^{1}$

To the best of our knowledge, there are only four cases of spontaneous gas gangrene reported due to $C$. perfringens in pediatric age group, three 
suffering from acute lymphoblastic leukemia, like our case, and one with non-Hodgkin lymphoma. ${ }^{3-5}$ Clinical findings and outcomes of these patients were shown in Table 1.

As the diagnosis is often delayed, spontaneous gas gangrene has high mortality. Before physicians can recognize it, the clinic has often progressed to such a late stage that bacteremia and sepsis have already developed. In the presence of severe abdominal pain or extremity pain with undefined cause in immunosuppressed patients, computed tomography can be useful to early determine gas gangrene. ${ }^{5}$ Presenting signs in our case were abdominal and leg pain, and were immediately followed by hemodynamic decompensation. Appropriate antibiotic treatment was given; however, surgical intervention could not have performed due to a very rapid deterioration of his status.

In our patient, isolation of E. coli at aerobic blood culture was also considered coinfection with C. perfringens; these microorganisms come from the intestinal flora because of the impaired mucosal barrier and mucosal leakage of organisms.

Mortality of $C$. perfringens bacteremia is reported to be $54 \%$ in pediatric age group. ${ }^{6}$ In a study including 40 adult patients, mortality rate and median time to death is reported to be $80 \%$ at 8 hours when hemolysis is present. ${ }^{7}$ In another study, including 50 adult patients, mortality rate is reported to be $74 \%$ while median time to death was 9.7 hours in C. perfringens sepsis complicated with hemolysis. ${ }^{8}$ Massive intravascular hemolysis is a well-known complication occurring $15 \%$ of all C. perfringens bacteremia and mortality is reported to be $90 \%$ in pediatric age group. ${ }^{9}$ The alfa toxin (phospholipase C), disrupt red cell membrane by hydrolyzing sphingomyelin and lecithin. It also lyses white blood cells, platelets, endothelial cells, and the plasma membranes of muscle cells. ${ }^{6,9}$ It plays an important role in hemolysis associated with $C$. perfringens. In our patient, C. perfringens bacteremia possibly resulted in

TABLE 1. Summary of spontaneous gas gangrene cases caused by Clostridium perfringens at the pediatric age group

\begin{tabular}{|c|c|c|c|c|c|}
\hline References & Minutti et al. ${ }^{3}$ & Temple et al. ${ }^{4}$ & Temple et al. ${ }^{4}$ & Dontchos et al. ${ }^{5}$ & Our case \\
\hline Age in years/gender & $7 / \mathrm{M}$ & $16 / \mathrm{M}$ & $18 / \mathrm{M}$ & $14 / \mathrm{F}$ & $17 / \mathrm{M}$ \\
\hline Underlying disease & $\begin{array}{l}\text { ALL (during } \\
\text { remission } \\
\text { induction) }\end{array}$ & $\begin{array}{l}\text { ALL (during } \\
\text { induction } \\
\text { chemotherapy } \\
\text { after first relapse) }\end{array}$ & $\begin{array}{l}\text { NHL (after } \\
\text { reinduction } \\
\text { chemotherapy } \\
\text { after first relapse) }\end{array}$ & $\begin{array}{l}\text { ALL (during } \\
\text { remission } \\
\text { induction) }\end{array}$ & $\begin{array}{l}\text { ALL (during } \\
\text { remission } \\
\text { induction) }\end{array}$ \\
\hline Presenting symptoms & Leg pain & Thigh pain & $\begin{array}{l}\text { Neutropenic fever } \\
\text { and calf pain }\end{array}$ & $\begin{array}{l}\text { Leg and } \\
\text { hip pain }\end{array}$ & $\begin{array}{l}\text { Abdominal } \\
\text { pain, leg pain }\end{array}$ \\
\hline $\begin{array}{l}\text { Abnormal finding on physical } \\
\text { examination at admission }\end{array}$ & Low grade fever & $\begin{array}{l}\text { Tenderness and } \\
\text { swelling at the } \\
\text { thigh, crepitus } \\
\text { at thigh }\end{array}$ & $\begin{array}{l}\text { Tenderness } \\
\text { and swelling } \\
\text { at thigh }\end{array}$ & $\begin{array}{l}\text { Tenderness } \\
\text { and swelling } \\
\text { at thigh }\end{array}$ & $\begin{array}{l}\text { Tenderness } \\
\text { and swelling } \\
\text { at thigh }\end{array}$ \\
\hline Concomitant hemolysis & No & No & No & No & Yes \\
\hline Antibiotics given & $\begin{array}{l}\text { Cefazolin, } \\
\text { ceftazidime, } \\
\text { gentamycine (for } \\
\text { neutropenic fever), } \\
\text { later piperacillin and } \\
\text { clindamycin added }\end{array}$ & $\begin{array}{l}\text { Cefepime, } \\
\text { clindamycin, } \\
\text { gentamicin }\end{array}$ & $\begin{array}{l}\text { Cefepime, } \\
\text { clindamycin, } \\
\text { gentamicin }\end{array}$ & $\begin{array}{l}\text { Ceftazidime, } \\
\text { gentamicin }\end{array}$ & $\begin{array}{l}\text { Meropenem, } \\
\text { clindamycin, } \\
\text { vancomycin }\end{array}$ \\
\hline Surgery & $\begin{array}{l}\text { During } \\
\text { debridement, died }\end{array}$ & $\begin{array}{l}\text { Left hip } \\
\text { disarticulation }\end{array}$ & $\begin{array}{l}\text { Above-the-knee } \\
\text { amputation }\end{array}$ & $\begin{array}{l}\text { Extensive } \\
\text { debridement } \\
\text { followed by } \\
\text { bilateral } \\
\text { above-the-knee } \\
\text { amputation }\end{array}$ & $\begin{array}{l}\text { Could not be } \\
\text { attempted } \\
\text { due to } \\
\text { hemodynamic } \\
\text { status }\end{array}$ \\
\hline Outcome & $\begin{array}{l}\text { Died, within the } \\
\text { first couple } \\
\text { of hours }\end{array}$ & $\begin{array}{l}\text { Died, } \\
18^{\text {th }} \text { hour }\end{array}$ & Survived & Survived & $\begin{array}{l}\text { Died, } \\
6^{\text {th }} \text { hour }\end{array}$ \\
\hline
\end{tabular}

M, male; F, female; ALL, acute lymphoblastic leukemia; NHL, nonhodgkin lymphoma. 
massive intravascular hemolysis and hemoglobin level rapidly decreased. Aggressive transfusions and positive inotropic treatments were executed; unfortunately his condition deteriorated and he died after cardiac arrest unresponsive to advanced life support protocols.

For neutropenic patients with unexplained excruciating pain, diagnosis of gas gangrene infection should be kept in mind. Even with early diagnosis and treatment, morbidity and mortality may not be prevented. High level of mortality rate is partly a result of accompanying massive intravascular hemolysis, which is a rare but well described complication of C. perfringens sepsis, probably triggering the acute hemodynamic decompensation.

\section{REFERENCES}

1. Bryant AE, Stevens DL. Clostridial myonecrosis: new insights in pathogenesis and management. Curr Infect Dis Rep 2010;12(5):383-91.
2. Stevens DL, Aldape MJ, Bryant AE. Life-threatening clostridial infections. Anaerobe 2012;18(2):254-9.

3. Minutti CZ, Immergluck LC, Schmidt ML. Spontaneous gas gangrene due to Clostridium perfringens. Clin Infect Dis 1999;28(1):159-60.

4. Temple AM, Thomas NJ. Gas gangrene secondary to Clostridium perfringens in pediatric oncology patients. Pediatr Emerg Care 2004;20(7):457-9.

5. Dontchos BN, Ricca R, MeehanJJ,SwansonJO.Spontaneous Clostridium perfringens myonecrosis: Case report, radiologic findings, and literature review. Radiol Case Rep 2015;8(3):806.

6. Stevens DL, Bryant AE. The role of clostridial toxins in the pathogenesis of gas gangrene. Clin Infect Dis 2002;35(Suppl 1):S93-100.

7. van Bunderen CC, Bomers MK, Wesdorp E, Peerbooms P, et al. Clostridium perfringens septicaemia with massive intravascular haemolysis: a case report and review of the literature. Neth J Med 2010;68(9):343-6.

8. Simon TG, Bradley J, Jones A, Carino G. Massive intravascular hemolysis from Clostridium perfringens septicemia: a review. Jntensive Care Med 2014;29(6):327-33 .

9. Caya JG, Truant AL. Clostridial bacteremia in thenon-infant pediatric population: a report of two cases and review of the literature. Pediatr Infect Dis J 1999;18(3):291-8. 